\title{
Clinicopathological characteristics of rectal carcinoid patients undergoing surgical resection
}

\author{
DAISUKE YAMAGISHI ${ }^{1}$, NAGAHIDE MATSUBARA ${ }^{1}$, MASAFUMI NODA $^{1}$, TOMOKI YAMANO ${ }^{1}$, \\ KIYOSHI TSUKAMOTO ${ }^{1}$, TAKASHI KUNO ${ }^{1}$, MIE HAMANAKA ${ }^{1}$, MASAYOSHI KOBAYASHI ${ }^{1}$, \\ HIROKI IKEUCHI $^{1}$, IKUO MATSUDA ${ }^{2}$, SEIICHI HIROTA ${ }^{2}$ and NAOHIRO TOMITA ${ }^{1}$ \\ ${ }^{1}$ Division of Lower GI, Department of Surgery; ${ }^{2}$ Department of Surgical Pathology, \\ Hyogo College of Medicine, Nishinomiya, Hyogo 663-8501, Japan
}

Received April 16, 2012; Accepted July 26, 2012

DOI: $10.3892 / \mathrm{ol} .2012 .868$

\begin{abstract}
The aim of this study was to clarify the clinical aspects, histopathological features and prognosis of patients with rectal carcinoids, focusing on properties associated with metastasis, in order to gain insights into appropriate management. A total of 20 patients (15 males, 5 females; mean age, 54.9 years; range, 23-71) who underwent surgery for rectal carcinoid tumors at the Department of Colorectal Surgery, Hyogo College of Medicine, between May 2000 and January 2011 were analyzed. Ki-67 immunostaining was performed in 13 cases with available tumor tissue specimens. Of the 20 patients, a radical operation including rectal resection with a lymphadenectomy was performed in 16 . The mean tumor size was $11.9 \mathrm{~mm}$ (3-25 mm) and lymph node metastasis was confirmed in 9 cases, including 3 with lesions no greater than $7 \mathrm{~mm}$ in diameter. Overall, $16(80 \%)$ of the tumors were localized in the submucosal layer and 4 (20\%) involved the proper muscle layer. Ki-67 labeling index and lymphovascular invasion were shown to be associated with lymph node and/or distant metastasis by multiple logistic regression analysis, but were not statistically significant in ANOVA findings. Lymph node metastasis from rectal carcinoids, even those smaller than $10 \mathrm{~mm}$ in diameter, was not a rare event. More attention should be given to decision-making, including the possibility of endoscopic resection for the treatment of rectal carcinoid tumors regardless of size.
\end{abstract}

Correspondence to: Dr Naohiro Tomita, Division of Lower GI, Department of Surgery, Hyogo College of Medicine, 1-1 Mukogawa-cho, Nishinomiya, Hyogo 663-8501, Japan E-mail: ntomita@hyo-med.ac.jp

Abbreviations: EMR, endoscopic mucosal resection; LAR, low anterior resection; CAA, colo-anal anastomosis; TAR, trans-anal local resection

Key words: rectal carcinoid, metastasis, Ki-67, lymphovascular invasion

\section{Introduction}

A rectal carcinoid is a rare tumor with a relatively good prognosis. In recent years, the reported incidence of rectal carcinoid tumors has been increasing, probably due to improvements in endoscopic diagnosis and/or treatment procedures (1). The malignant potential and prognosis of rectal carcinoids have been reported to be mainly associated with tumor size (2-8). Tumors smaller than $10 \mathrm{~mm}$ in size are usually treated with an endoscopic procedure, although several authors have reported that even small rectal carcinoids have the potential to metastasize (5,9-12). With regard to the organ distribution of these tumors, the most frequent site is the gastrointestinal tract, followed by the bronchopulmonary system, while for those within the digestive organs the most frequent site is the small intestine, followed by the rectum and stomach $(13,14)$.

Although the survival of patients with colorectal carcinoid tumors without metastasis is better than that of those with colorectal adenocarcinomas, survival is equally poor for the two types of malignancy if metastasis occurs $(2,15,16)$. Several factors, including tumor size, depth of invasion, presence of lymphovascular invasion, presence of central depression and $\mathrm{Ki}-67$ ratio, have been reported to be associated with metastasis $(2-6,16,17)$. Tumors smaller than $10 \mathrm{~mm}$ in size without infiltration to the proper muscle layer can usually be removed in an endoscopic procedure. If invasion of a lymph node or blood vessels is noted in the histological findings, additional surgical resection of the rectum with the meso-rectal lymph nodes is recommended $(2,18)$.

Most patients with a rectal carcinoid are treated with endoscopic resection and then undergo no further treatment, while some undergo trans-anal local resection or trans-abdominal surgery. A few authors have warned that a small rectal carcinoid has the potential to metastasize to the lymph nodes or other distant organs $(9-11,19)$, while others have reported that small rectal carcinoids were managed endoscopically without recurrence $(8,20-22)$.

Appropriate treatment for cases of carcinoids smaller than $10 \mathrm{~mm}$ in diameter remains controversial with regard to whether local endoscopic resection or radical surgery is indicated. In order to clarify this point, we analyzed the clinicopathological features of patients with rectal carcinoids 


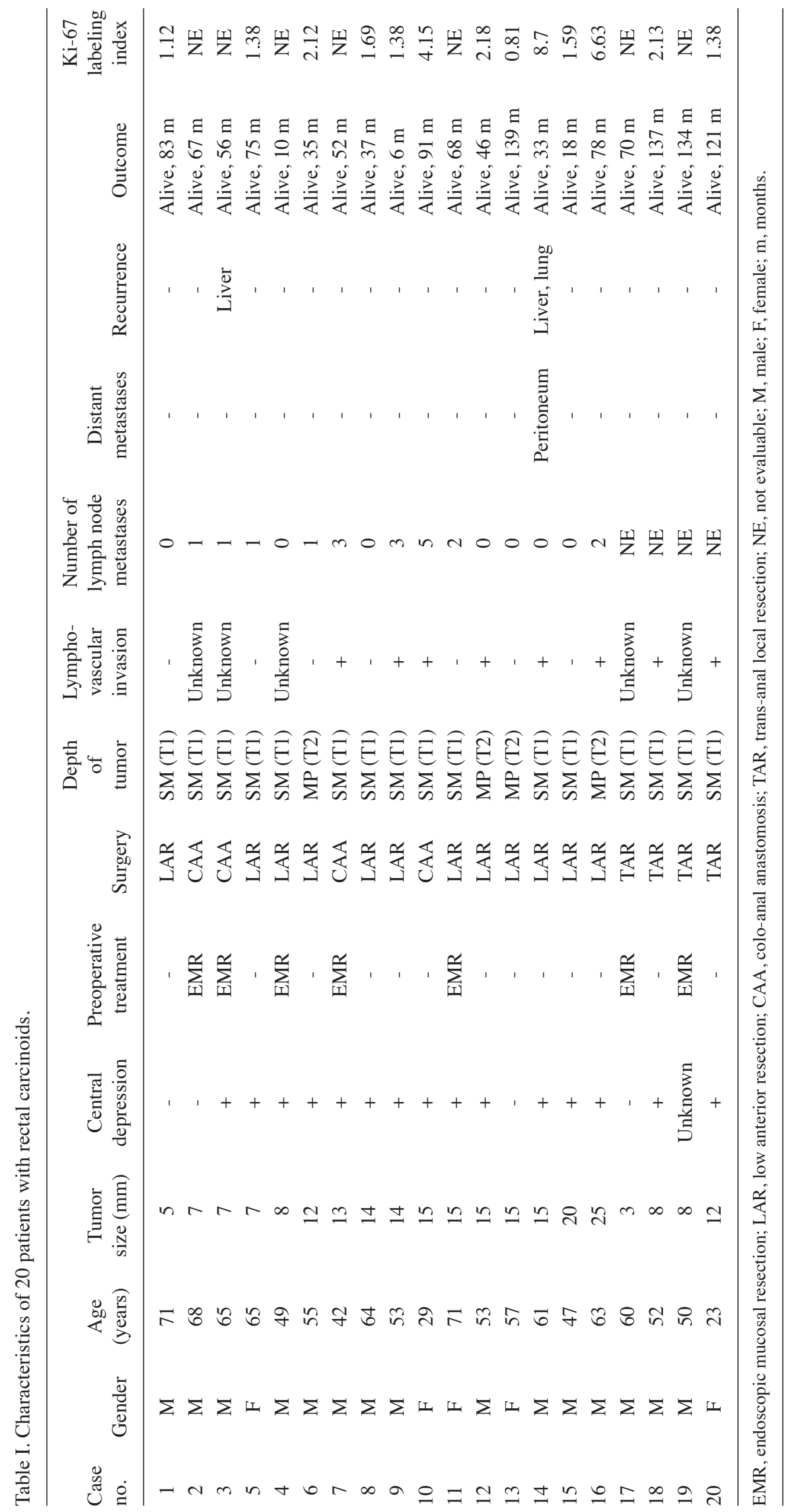


Table II. Clinical and surgical characteristics of 20 patients with rectal carcinoids.

\begin{tabular}{|c|c|c|c|}
\hline \multirow[b]{2}{*}{ Characteristic } & \multirow[b]{2}{*}{$\begin{array}{c}\text { All } \\
\text { patients } \\
(\mathrm{n}=20)\end{array}$} & \multicolumn{2}{|c|}{ Surgical procedures } \\
\hline & & $\begin{array}{l}\text { Radical } \\
\text { surgery } \\
(\mathrm{n}=16)\end{array}$ & $\begin{array}{l}\text { Local } \\
\text { resection } \\
(\mathrm{n}=4)\end{array}$ \\
\hline \multicolumn{4}{|l|}{ Gender } \\
\hline Male & 15 & 12 & 3 \\
\hline Female & 5 & 4 & 1 \\
\hline \multicolumn{4}{|l|}{ Age (years) } \\
\hline Mean & 54.9 & 57.1 & 46.3 \\
\hline Range & $23-71$ & $29-71$ & $23-60$ \\
\hline \multicolumn{4}{|l|}{$\begin{array}{l}\text { Follow-up time } \\
\text { (months) }\end{array}$} \\
\hline Mean & 68 & 56 & 116 \\
\hline Range & $6-139$ & $6-139$ & $70-137$ \\
\hline \multicolumn{4}{|l|}{ Tumor site } \\
\hline Lower rectum & 20 & 16 & 4 \\
\hline \multicolumn{4}{|l|}{ Tumor size (mm) } \\
\hline Mean & 11.9 & 12.9 & 7.8 \\
\hline Range & $3-25$ & $5-25$ & $3-12$ \\
\hline \multicolumn{4}{|l|}{ Tumor depth } \\
\hline SM (T1) & 16 & 12 & 4 \\
\hline MP (T2) & 4 & 4 & 0 \\
\hline \multicolumn{4}{|l|}{ Metastasis } \\
\hline Lymph node & 9 & 9 & $\mathrm{NE}$ \\
\hline Distant & 2 & 2 & $\mathrm{NE}$ \\
\hline \multicolumn{4}{|c|}{$\begin{array}{l}\text { Preoperative } \\
\text { endoscopic treatment }\end{array}$} \\
\hline Yes & 7 & 5 & 2 \\
\hline No & 13 & 11 & 2 \\
\hline
\end{tabular}

NE, not evaluable.

who underwent surgical resection, focusing on the correlations among these factors and outcomes, including lymph node metastasis, recurrence and survival.

\section{Patients and methods}

Patients. A total of 20 patients with rectal carcinoids who underwent surgical resection between 2000 and 2011 were identified from a database maintained at the Division of Lower GI,Department of Surgery, Hyogo College of Medicine (Hyogo, Japan). Follow-up examinations were performed until the time of recurrence or closing date of the study (October 30, 2011) and the mean follow-up period was 68 months. Demographic, clinical and pathological data, including gender, age, tumor size $(\mathrm{mm})$, depth of invasion, presence of lymphovascular invasion, method of resection, presence of lymph node metastasis, presence and site of distant metastasis, presence of recurrence and prognosis, were collected. The presence of lymphovascular invasion was evaluated in all cases, with the exception of
5 who underwent endoscopic resection at other institutions and whose specimens were unavailable (Table I). All study protocols were approved by the institutional reviews board at Hyogo College of Medicine and informed consent and agreement for use of patient data were obtained prior to surgery.

Statistics. The correlation between lymph node metastasis and other clinicopathological factors was subjected to multiple logistic regression analysis. We analyzed risk factors (tumor size, tumor depth, presence of lymphovascular invasion, presence of central depression, Ki-67 ratio) in 16 patients who underwent surgery with a lymphadenectomy. Actuarial disease-free survival (DFS) was estimated using the KaplanMeier method. SPSS version 19.0 (SPSS, Tokyo, Japan) was used to perform all analyses.

Ki-67 immunostaining. The specimens were diagnosed by at least 2 pathologists approved by the Japanese Society of Pathology. Ki-67 immunostaining was performed in 13 cases, as the specimens from 7 cases were unavailable since those patient had been treated in other institutions. The Ki-67 labeling index was determined as the ratio of Ki-67-positive cells among the total tumor cells examined. In each case, at least 3 representative areas were selected to count the number of cells, with the total number of tumor cells examined $>1,000$.

\section{Results}

Patients and clinicopathological features. All patients were Japanese and consisted of 15 males and 5 females, with a mean age of 54.9 years (range, 23-71) at diagnosis. The site of disease in all 20 cases was the lower rectum, which was defined as the area below the peritoneal reflection. The mean tumor size was $11.9 \mathrm{~mm}$ (range, 3-25). Overall, $16(80 \%)$ tumors were limited to the submucosal layer, while $4(20 \%)$ involved the proper muscle layer. These characteristics are presented in Table II.

Treatment. Endoscopic treatment was performed prior to surgery in 7 patients (cases 2, 3, 5, 7, 11, 17 and 19). Trans-anal local resection was performed in 4 patients (cases 17-20) and each of those cases was followed for $>70$ months (mean, 116), with no recurrence identified at the time of writing. Radical surgery consisting of rectal resection with a lymphadenectomy was performed in 16 (cases 1-16) of the 20 patients (Table II). Surgery was also performed in 5 cases (cases 1-5) whose tumors were $<10 \mathrm{~mm}$ in size, due to incomplete resection during endoscopic treatment in 3 (cases 2, 3 and 5), co-existence of sigmoid diverticulum (case 1) and co-existence of sigmoid colon carcinoma (case 4).

Metastasis and related risk factors. A total of 10 patients had synchronous or metachronous metastasis, of whom 9 had synchronous lymph node metastasis. Furthermore, 2 patients had distant metastasis (case 3, liver; case 14, liver, lung and peritoneum). In 3 of the 10 cases with metastasis to the lymph nodes and/or distant organs, the tumor size was $<10 \mathrm{~mm}$, with the smallest $7 \mathrm{~mm}$. Depth of tumor invasion, presence of lymphovascular invasion, presence of central depression and Ki-67 labeling index (>2\%) had no significant association with 
Table III. Univariate analysis of factors associated with metastasis.

\begin{tabular}{|c|c|c|c|c|c|}
\hline \multirow[b]{2}{*}{ Factor } & \multicolumn{5}{|c|}{ Patients with lymphadenectomy $(n=16)$} \\
\hline & $\begin{array}{l}\text { With metastases } \\
\qquad(\mathrm{n}=10)\end{array}$ & $\begin{array}{l}\text { Without metastases } \\
\qquad(\mathrm{n}=6)\end{array}$ & $\begin{array}{l}\text { Total } \\
(\mathrm{n}=16)\end{array}$ & P-value & (r) \\
\hline \multicolumn{6}{|l|}{ Tumor size $(\mathrm{mm}), \mathrm{n}(\%)$} \\
\hline $1-10$ & $3(60)$ & $2(40)$ & 5 & 0.898 & 0.16 \\
\hline$>11$ & $7(64)$ & $4(36)$ & 11 & & \\
\hline \multicolumn{6}{|l|}{ Tumor depth, n (\%) } \\
\hline $\mathrm{T} 1$ & $8(67)$ & $4(33)$ & 12 & 0.582 & -0.149 \\
\hline $\mathrm{T} 2$ & $2(50)$ & $2(50)$ & 4 & & \\
\hline \multicolumn{6}{|c|}{ Lymphovascular invasion, $\mathrm{n}(\%)$} \\
\hline Positive & $4(66)$ & $2(33)$ & 6 & 0.159 & 0.415 \\
\hline Negative & $3(43)$ & $4(57)$ & 7 & & \\
\hline Not evaluable & $3(100)$ & $0(0)$ & 3 & & \\
\hline \multicolumn{6}{|c|}{ Central depression, n (\%) } \\
\hline Positive & $9(69)$ & $4(31)$ & 13 & 0.277 & 0.289 \\
\hline Negative & $1(33)$ & $2(67)$ & 3 & & \\
\hline \multicolumn{6}{|c|}{ Ki-67 labeling index (\%), n (\%) } \\
\hline$<2$ & $2(33)$ & $4(67)$ & 6 & 0.148 & 0.467 \\
\hline$\geq 2$ & $4(80)$ & $1(20)$ & 5 & & \\
\hline Not evaluable, $\mathrm{n}(\%)$ & $4(80)$ & $1(20)$ & 5 & & \\
\hline Mean & 4.06 & 1.48 & & & \\
\hline Range & $1.38-8.70$ & $0.81-2.18$ & & & \\
\hline
\end{tabular}

(r), Pearson product-moment correlation coefficient.

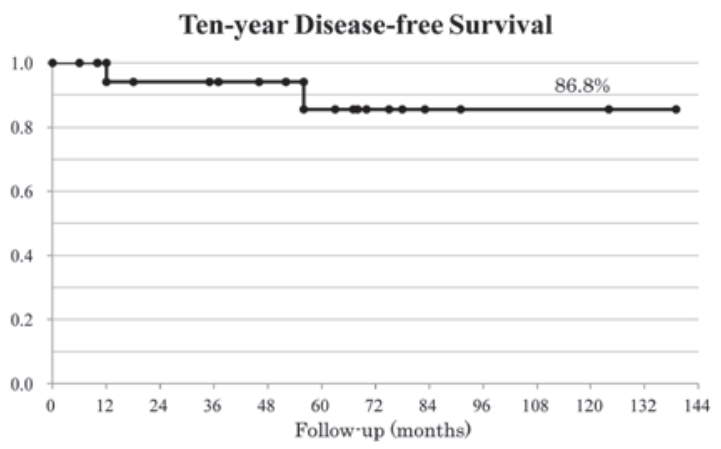

Figure 1. Disease-free survival of rectal carcinoid patients. The 10-year disease-free survival rate of rectal carcinoid patients was calculated to be $86.8 \%$.

metastasis, as shown by ANOVA. However, Ki-67 labeling index and lymphovascular invasion were shown to be independently correlated with lymph node and/or distant metastasis by multiple logistic regression analysis (Table III).

Prognosis. The mean follow-up period was 68 months (range, 6-139). At the time of writing, all patients are alive. Furthermore, 4 patients who underwent trans-anal local resection are alive after follow-up examinations for $>70$ months without relapse. Relapse was confirmed in 2 cases (cases 3 and 14). The 10-year DFS rate was $86.8 \%$ (Kaplan-Meier method; Fig. 1).

\section{Discussion}

A rectal carcinoid is a relatively rare tumor, although studies concerning clinical and/or pathological features have been increasing in recent years and several factors associated with metastasis of this tumor have been investigated and discussed $(2-8,16,17,23)$. It is generally considered that tumor size and the presence of lymphovascular invasion are the most important predictive factors for metastatic disease associated with a rectal carcinoid (2). The most detailed study was that conducted by Maggard et al in 2004, who investigated 11,427 carcinoid cases. Of those, 1,217 patients with rectal carcinoids had a 5-year survival rate of $87.5 \%$ (15). Regretfully, details of metastasis were not described in that study. Soga performed a large study of 1,271 cases of rectal carcinoid, in which the rate of metastasis from rectal carcinoid tumors smaller than $10 \mathrm{~mm}$ in diameter was $5.5 \%$ (5). However, large numbers of cases in those studies received endoscopic treatment. For patients with small rectal carcinoids who underwent endoscopic treatment, the rate of lymph node metastasis is reported to be low $(22,25,26)$. By contrast, the rate of lymph node metastasis from a small rectal carcinoid in patients who underwent surgery with a lymphadenectomy has been reported to be $66 \%$ (27). Taking these findings into consideration, the size of a rectal carcinoid tumor is the most established risk factor for surgical resection thus far presented, though it should be noted that the reported results show great differences. It must be concluded that the true rate of 
metastasis to the lymph nodes is unknown without investigating cases that underwent surgery with a lymphadenectomy.

In the present study, we investigated patients who underwent surgical resection with a lymphadenectomy, including those with small tumors less than $10 \mathrm{~mm}$ in diameter who received the treatment for pathognomonic reasons. Our results showed a high rate $(55 \%)$ of lymph node metastasis, while in cases with tumors smaller than $10 \mathrm{~mm}$ the metastasis rate reached $60 \%$. However, all patients were alive at the time of writing and their prognoses are good. Therefore, we consider that the growth rate of a rectal carcinoid tumor is associated with metastatic presence.

The Ki-67 index is known to be a marker of proliferative capacity in cases of breast cancer and other various malignancies (28), while certain authors have noted that Ki-67 is useful for a metastatic index of carcinoid tumors (4,29-31). Hotta et al reported that $\mathrm{Ki}-67$ is a reliable microscopic marker to predict the metastatic potential of rectal carcinoids (7). Therefore, we also determined Ki-67 labeling index values to clarify their significance for evaluating the metastatic potential of rectal carcinoids. Our findings showed that the $\mathrm{Ki}-67$ ratio is a reliable histological parameter to predict the metastatic behavior of rectal carcinoids. As the Ki-67 values of rectal carcinoids are relatively low compared with breast cancer, we speculate that the growth rate of rectal carcinoids is relatively slow. Even if microscopic metastasis remains following resection of the primary tumor, a long period is likely to pass before metastasis becomes clinically evident. To the best of our knowledge, the diameter of the smallest rectal carcinoid tumor with metastasis reported is $3 \mathrm{~mm}$ in diameter (32).

In conclusion, rectal carcinoids smaller than $10 \mathrm{~mm}$ have a high risk of lymph node or distant metastasis (60\%), thus careful decisions with regard to treatment and follow-up are needed. Lymphovascular invasion and $\mathrm{Ki}-67$ ratio may be good predictive markers for metastasis, and we expect the usefulness of the latter, especially for surgery indication following endoscopic treatment, to be established. However, the number of rectal carcinoid tumors examined in the present study is small and additional studies with a larger number of samples are needed.

\section{Acknowledgements}

A grant-in-aid for cancer research from the Ministry of Education, Science, Sports and Culture of Japan to Naohiro Tomita supported this study.

\section{References}

1. Soga J: Carcinoids and their variant endocrinomas. An analysis of 11842 reported cases. J Exp Clin Cancer Res 22: 517-530, 2003.

2. Modlin IM, Lye KD and Kidd M: A 5-decade analysis of 13,715 carcinoid tumors. Cancer 97: 934-959, 2003.

3. Shields CJ, Tiret E and Winter DC: Carcinoid tumors of the rectum: a multi-institutional international collaboration. Ann Surg 252: 750-755, 2010.

4. Jetmore AB, Ray JE, Gathright JB Jr, McMullen KM, Hicks TC and Timmcke AE: Rectal carcinoids: the most frequent carcinoid tumor. Dis Colon Rectum 35: 717-725, 1992.

5. Soga J: Early-stage carcinoids of the gastrointestinal tract: an analysis of 1914 reported cases. Cancer 103: 1587-1595, 2005.

6. Konishi T, Watanabe T, Kishimoto J, Kotake K, Muto T and Nagawa H: Prognosis and risk factors of metastasis in colorectal carcinoids: results of a nationwide registry over 15 years. Gut 56: 863-868, 2007.
7. Hotta K, Shimoda T, Nakanishi Y and Saito D: Usefulness of $\mathrm{Ki}-67$ for predicting the metastatic potential of rectal carcinoids. Pathol Int 56: 591-596, 2006.

8. Soga J: Carcinoids of the rectum: an evaluation of 1271 reported cases. Surg Today 27: 112-119, 1997.

9. Tomoda H, Furusawa M, Hayashi I and Okumura K: A rectal carcinoid tumor of less than $1 \mathrm{~cm}$ in diameter with lymph node metastasis: a case report and a review of the literature. Jpn J Surg 20: 468-471, 1990

10. Akasu T, Moriya Y and Sugihara K: Transrectal ultrasonography of a small rectal carcinoid tumor with lymph node metastasis: a case report. Jpn J Clin Oncol 26: 112-115, 1996.

11. Saito T, Ikenaga M, Yasui M, et al: A case of $7 \mathrm{~mm}$ rectal carcinoid with lymph node metastasis. Gan To Kagaku Ryoho 36: 2251-2253, 2009 (In Japanese).

12. Onozato Y, Kakizaki S, Iizuka H, Sohara N, Mori M and Itoh H: Endoscopic treatment of rectal carcinoid tumors. Dis Colon Rectum 53: 169-176, 2010.

13. Hassan MM, Phan A, Li D, Dagohoy CG, Leary C and Yao JC: Risk factors associated with neuroendocrine tumors: A U.S.-based case-control study. Int J Cancer 123: 867-873, 2008.

14. Fahy BN, Tang LH, Klimstra D, et al: Carcinoid of the rectum risk stratification (CaRRs): a strategy for preoperative outcome assessment. Ann Surg Oncol 14: 1735-1743, 2007.

15. Maggard MA, O'Connell JB and Ko CY: Updated populationbased review of carcinoid tumors. Ann Surg 240: 117-122, 2004.

16. Zhang YQ, Zhou PH, Xu MD, et al: Long-term efficacy of endoscopic excision of rectal carcinoids. Zhonghua Wei Chang Wai Ke Za Zhi 11: 421-423, 2008 (In Chinese).

17. Landry CS, Brock G, Scoggins CR, McMasters KM and Martin RC II: A proposed staging system for rectal carcinoid tumors based on an analysis of 4701 patients. Surgery 144: 460-466, 2008.

18. Merg A, Wirtzfeld D, Wang J, Cheney R, Dunn KB and Rajput A: Viability of endoscopic and excisional treatment of early rectal carcinoids. J Gastrointest Surg 11: 893-897, 2007.

19. Fujimoto Y, Oya M, Kuroyanagi H, et al: Lymph-node metastases in rectal carcinoids. Langenbecks Arch Surg 395: 139-142, 2008.

20. Scholzen T and Gerdes J: The Ki-67 protein: from the known and the unknown. J Cell Physiol 182: 311-322, 2000.

21. Jung SY, Han W, Lee JW, et al: Ki-67 expression gives additional prognostic information on St. Gallen 2007 and Adjuvant! Online risk categories in early breast cancer. Ann Surg Oncol 16: 1112-1121, 2009.

22. Moyana TN, Xiang J, Senthilselvan A and Kulaga A: The spectrum of neuroendocrine differentiation among gastrointestinal carcinoids: importance of histologic grading, MIB-1, p53, and bcl-2 immunoreactivity. Arch Pathol Lab Med 124: 570-576, 2000.

23. Sokmensuer C, Gedikoglu G and Uzunalimoglu B: Importance of proliferation markers in gastrointestinal carcinoid tumors: a clinicopathologic study. Hepatogastroenterology 48: 720-723, 2001.

24. Okumura Y, Maruta M, Maeda K, et al: Minute carcinoid tumor in the rectum with liver metastasis. Gan To Kagaku Ryoho 24 (Suppl 2): 307-312, 1997 (In Japanese).

25. Scherübl H: Rectal carcinoids are on the rise: early detection by screening endoscopy. Endoscopy 41: 162-165, 2009.

26. Heah SM, Eu KW, Ooi BS, Ho YH and Seow-Choen F: Tumor size is irrelevant in predicting malignant potential of carcinoid tumors of the rectum. Tech Coloproctol 5: 73-77, 2001.

27. Stinner B, Kisker O, Zielke A and Rothmund M: Surgical management for carcinoid tumors of small bowel, appendix, colon, and rectum. World J Surg 20: 183-188, 1996.

28. Ramage JK, Goretzki PE, Manfredi R, et al; Consensus Conference participants: Consensus guidelines for the management of patients with digestive neuroendocrine tumours: well-differentiated colon and rectum tumour/carcinoma. Neuroendocrinology 87: 31-39, 2008.

29. Koura AN, Giacco GG, Curley SA, Skibber JM, Feig BW and Ellis LM: Carcinoid tumors of the rectum: effect of size, histopathology, and surgical treatment on metastasis free survival. Cancer 79: 1294-1298, 1997.

30. Mashimo Y, Matsuda T, Uraoka T, et al: Endoscopic submucosal resection with a ligation device is an effective and safe treatment for carcinoid tumors in the lower rectum. J Gastroenterol Hepatol 23: 218-221, 2008.

31. Shinohara T, Hotta K and Oyama T: Rectal carcinoid tumor, $6 \mathrm{~mm}$ in diameter, with lymph node metastases. Endoscopy 40 (Suppl 2): E40-E41, 2008.

32. Moon SH, Hwang JH, Sohn DK, et al: Endoscopic submucosal dissection for rectal neuroendocrine (carcinoid) tumors. J Laparoendosc Adv Surg Tech A 21: 695-699, 2011. 